\title{
Avaliação em laboratório e em campo da deformação permanente de pavimentos asfálticos do Ceará e de São Paulo
}

\author{
Juceline Batista dos Santos Bastos ${ }^{1}$, Rômulo Luiz Borges², Jorge Barbosa Soares ${ }^{3}$ \\ e Luis Miguel Gutierrez Klinsky4.
}

\begin{abstract}
Resumo: A deformação permanente é um dos defeitos mais comuns que ocorrem em pavimentos asfálticos brasileiros, reduzindo o conforto ao rolamento, a segurança do usuário, e aumentando custos operacionais. O presente trabalho tem como objetivo principal investigar um trecho monitorado (300 metros) da BR-222, localizado no Estado do Ceará, e um trecho monitorado da BR-116, no Estado de São Paulo. Para tanto, verificou-se o comportamento das misturas asfálticas adotadas nessas rodovias, tanto em laboratório por meio dos ensaios uniaxial de carga repetida e Triaxial Stress Sweep (TSS), como em campo por meio da verificação do afundamento de trilha de roda. A mistura cearense foi dosada pelo método Marshall e foi utilizado o CAP 50/70 da Lubnor. A mistura paulista foi dosada pela metodologia Superpave e foi utilizado o CAP 30/45 da Replan. Os resultados apontam que, em campo, quatro meses após liberação do trecho, a mistura asfáltica do Ceará apresentou afundamentos de trilha de roda. Em laboratório, a mesma mistura também se mostrou frágil para os dois ensaios de deformação permanente analisados. A mistura asfáltica de São Paulo apresentou até abril de 2015 (período investigado), após 3,5 anos da execução, um bom desempenho em campo, sem afundamento de trilha de roda. Em laboratório, de acordo com o ensaio uniaxial de carga repetida essa mistura apresentou um Flow Number (FN) adequado para um tráfego pesado, na extensão em que é válida a aplicação dos limites sugeridos nacionalmente. Porém, no ensaio TSS, essa mistura não ultrapassou o ensaio de referência, impossibilitando a previsão da evolução dessa falha e sugerindo fragilidade quanto à deformação permanente, em desacordo com o resultado apresentado em campo até o momento.
\end{abstract}

Palavras-chave: deformação permanente, trechos monitorados, uniaxial de carga repetida, Triaxial Stress Sweep.

\begin{abstract}
Rutting is a common distress in Brazilian asphalt pavements, reducing the driving comfort and safety, and increasing operational costs. This study aims to investigate a monitored test section (300 meters) of BR-222 in the state of Ceará, and another one of BR-116 in the state of São Paulo. It was observed the behavior of asphalt mixtures of these highways, in the laboratory by means of the uniaxial load repeated test and the Triaxial Stress Sweep (TSS), as well as in the field by making rutting measurements over time. The mixture in Ceará was designed by the Marshall method with an asphalt cement 50/70 from Petrobras/Lubnor. The mixture in São Paulo was designed by the Superpave methodology with an asphalt cement 30/45 from Petrobras/Replan. The results show that in the field, after only four months of opening to traffic, the mixture of Ceará presented wheel track rutting. In the laboratory, this mixture was also considered inappropriate by both rutting tests analyzed. The mixture of São Paulo presented until April 2015 (observation period), after 3.5 years in service, a good performance in the field, without observable rutting. In the laboratory, according to the uniaxial load repeat test this mixture presented a Flow Number (FN) compatible to heavy traffic. However, when considering the TSS test, this mixture fails to pass the reference test, making it impossible to preview the evolution of the investigated failure and suggesting susceptibility to rutting, which is not in line with the results presented in the field up to this moment.
\end{abstract}

Keywords: Rut, test sections, repeated uniaxial load, Triaxial Stress Sweep.

\section{INTRODUÇÃO}

Nos últimos anos, a ocorrência prematura e/ou excessiva da deformação permanente nos pavimentos asfálticos tem sido motivo de preocupação entre técnicos e pesquisadores brasileiros da área de pavimentação. Dentre os diversos tipos de defeitos a que um pavimento está sujeito, o afundamento em trilha de roda da camada de rolamento é um dos mais importantes. Esse tipo de defeito além de propiciar uma degradação acelerada da estrutura do pavimento,

\footnotetext{
1 Juceline Batista dos Santos Bastos, Universidade Federal do Ceará-

UFC (jucelinebatista@hotmail.com)

2 Rômulo Luiz Borges, Universidade Federal do Ceará-UFC,

(borges@det.ufc.br)

3 Jorge Barbosa Soares, Universidade Federal do Ceará-UFC

(jsoares@det.ufc.br)

${ }^{4}$ Luis Miguel Gutierrez Klinsky, Centro de Pesquisas Rodoviárias - CCR

NovaDutra - Grupo CCR. (luis.gutierrez@grupoccr.com.br)
}

Manuscrito recebido em 01/05/2015 e aprovado para publicação em 22/07/2015.

Este artigo é parte de TRANSPORTES v. 23, n. 3, 2015. ISSN: 2237-1346 (online). DOI: 10.14295/transportes. v23i3.914 reduz consideravelmente o conforto ao rolamento, a segurança do usuário, e aumenta os custos operacionais.

A deformação permanente nos revestimentos asfálticos é caracterizada por depressões longitudinais nas trilhas de roda, as quais aumentam com a solicitação das cargas repetidas impostas pelo tráfego de veículos. Os materiais das camadas abaixo do revestimento podem apresentar deformações permanentes, sobretudo por densificação adicional pelo tráfego e por ruptura ao cisalhamento. Estes dois aspectos são importantes no projeto do pavimento. A consolidação das camadas do pavimento é tratada pelo grau de compactação necessário em cada camada. Portanto, a compactação adicional em pavimentos bem construídos é mínima. O componente de cisalhamento da deformação também é tratado no dimensionamento oficial que utiliza o CBR (California Bearing Ratio), mas apenas no subleito (Uzan, 2004), já que a estrutura do pavimento é concebida para protegê-lo. No caso das misturas asfálticas dos revestimentos, a deformação permanente ocorre devido ao fluxo do material (viscoelástico ou viscoplástico), que ocorre, sobretudo em temperaturas acima de $60^{\circ} \mathrm{C}$, panorama comum 
no Ceará, no qual é observada a redução da rigidez do ligante (Bernucci et al., 2010).

O Brasil ainda não possui estabelecido um ensaio de caracterização da deformação permanente de misturas asfálticas, embora esteja previsto o desenvolvimento de uma norma para 2015 no âmbito da Comissão de Asfalto do IBP (Instituto Brasileiro de Petróleo, Gás e Biocombustíveis). Um ensaio realizado no país é o uniaxial de carga repetida (também denominado de creep dinâmico) para determinação do chamado Flow Number (FN), e também o ensaio de placas por meio de simuladores de laboratório. No entanto, o FN pode não ser o parâmetro mais adequado a ser extraído do ensaio em questão, pela possível variação com, por exemplo, o confinamento do corpo de prova (Borges, 2014). Ademais, a ausência de informações sobre tal parâmetro das misturas em campo instiga a comunidade científica e técnica a refinar critérios de aceitação de misturas asfálticas para deformação permanente no ensaio uniaxial de carga repetida sob diferentes níveis de tráfego.

Para a presente pesquisa, além do ensaio uniaxial de carga repetida foi realizado o ensaio triaxial de varredura de tensões (Triaxial Stress Sweep - TSS) (Choi, 2013), que é um protocolo de ensaio sob condições de confinamento, a fim de melhor se aproximar das condições encontradas em campo. Além de considerar o confinamento, o ensaio TSS possibilita o uso do Shift Model, derivado do modelo incremental viscoplástico (Subramanian, 2011; Choi, 2013), que analisa o comportamento de misturas asfálticas quanto à resistência à deformação permanente. A associação do Shift Model ao programa LVECD (Layered Viscoelastic Continuum Damage) permite a previsão de desempenho de pavimentos asfálticos quanto a essa falha. Borges (2014) utilizou esse protocolo de ensaio e aplicou o Shift Model para analisar o comportamento de uma mistura asfáltica quanto à resistência à deformação permanente. No entanto, o confronto do ensaio triaxial de varredura de tensões em laboratório com misturas monitoradas em campo ainda é uma carência na literatura, mesmo internacional.

Dessa forma, o objetivo deste trabalho é investigar o comportamento de misturas asfálticas quanto à deformação permanente ao longo do tempo e do carregamento, a partir dos ensaios TSS e uniaxial de carga repetida em laboratório, associado ao monitoramento em campo.

\section{FUNDAMENTAÇÃO TEÓRICA}

\subsection{Uniaxial de Carga Repetida}

O ensaio mais comumente realizado no país para caracterização da deformação permanente de misturas asfálticas é o uniaxial de carga repetida (Nascimento, 2008; Onofre, 2012; Borges, 2014; Pazos, 2015). Nesse ensaio a mistura asfáltica é submetida a um carregamento cíclico de compressão e a deformação permanente acumulada é obtida em função do número de ciclos. Tanto no Brasil, quanto internacionalmente, o ciclo consiste de um pulso haversine de 0,1 s seguido por um repouso de $0,9 \mathrm{~s}$, a uma temperatura especificada $\left(60^{\circ} \mathrm{C}\right)$ (Witczak et al., 2002).

A deformação permanente acumulada $\left(\varepsilon_{\mathrm{p}}\right)$ pode ser dividida em três regiões: primária, secundária e terciária. $\mathrm{O}$ número de ciclos onde começa a região terciária (cisalhamento com volume constante) é referido como Flow Number (Figura 1). O FN é o número do ciclo em que a taxa de deformação plástica é mínima e a partir do qual o CP atinge a ruptura (Witczak et al., 2002). O ensaio é finalizado em três casos: (i) quando o FN é atingido, (ii) quando o ciclo de número 10.000 é atingido ou (iii) quando a mistura atinge $5 \%$ de deformação para ensaios confinados e $2 \%$ de deformação para ensaios não confinados (Dongre et al., 2009). Essas regiões se comportam da seguinte forma: (i) na região primária, a densificação da amostra ocorre a uma taxa elevada, (ii) na região secundária, a taxa de deformação é praticamente constante e (iii) na região terciária, a amostra rompe.

Buscando caracterizar de forma mais realista a deformação permanente, na África do Sul, Boateng e Maina (2012) propuseram um protocolo de ensaio uniaxial para avaliação de misturas asfálticas que foi adotado no método mecanístico-empírico daquele país, incluindo diferentes níveis de tensões e de temperaturas. Nesse protocolo os autores adotaram 4 níveis de tensão axial (69, 138, 207 e $276 \mathrm{kPa})$ em 3 temperaturas distintas $\left(25,40\right.$ e $\left.55^{\circ} \mathrm{C}\right)$. Cada par de temperatura e tensão exige novos CPs, tendo em vista que o ensaio é destrutivo.

Alguns autores recomendam critérios de FN para misturas asfálticas em diferentes níveis de tráfego. Em $\mathrm{Na-}$ tional Cooperative Highway Research Program (NCHRP) Report 673 (Advanced Asphalt Technologies, 2011), critérios de FN foram desenvolvidos com base na avaliação de 6 pistas da Federal Highway Administration (FHWA) e de 27 misturas em laboratório. Esses critérios foram incluídos no manual de misturas asfálticas a quente, desenvolvido no referido projeto. Bonaquist (2012) considerou tais critérios excessivamente conservadores, tendo em vista o desempenho dessas misturas em campo. O autor atribuiu a provável discrepância à utilização do algoritmo de diferenças finitas para obtenção do FN. Assim, Bonaquist (2012) optou em utilizar o modelo de Francken (1977) ao propor critérios de FN para misturas utilizadas em cruzamentos. Nascimento (2008) recomendou critérios de FN concomitantemente com critérios de Compaction Densification Index (CDI) e Traffic Densification Index (TDI) de misturas asfálticas densas utilizadas como camada de revestimento em rodovias brasileiras. A Tabela 1 apresenta os critérios de FN sugeridos nessas pesquisas.

\subsection{Triaxial de Varredura de Tensões}

O Triaxial Stress Sweep (TSS, triaxial de varredura de tensões) é um ensaio de compressão cíclica sob pressão confinante constante que emprega um pulso de carga haversine seguido por um período de repouso. Esse ensaio vem sendo adotado em modelos mecânicos avançados para investigação da deformação permanente (Gibson e Schwartz, 2006; Yun, 2008; Subramanian, 2011; Choi et al., 2012; Lacroix, 2013; Choi, 2013; Borges, 2014; Lacroix e Kim, 2014; Choi e Kim, 2014), pois as cargas cíclicas de amplitude constante fornecem características específicas sobre o material. Esse ensaio é realizado em duas etapas: na primeira etapa é realizado o ensaio de referência Triaxial $R e$ peated Load Permanent Deformation (TRLPD, ensaio triaxial de deformação permanente com carregamento repetido) e em seguida são realizados os ensaios Multiple Stress Sweep (MSS, ensaios múltiplos de varredura de tensões) (Choi, 2013). 


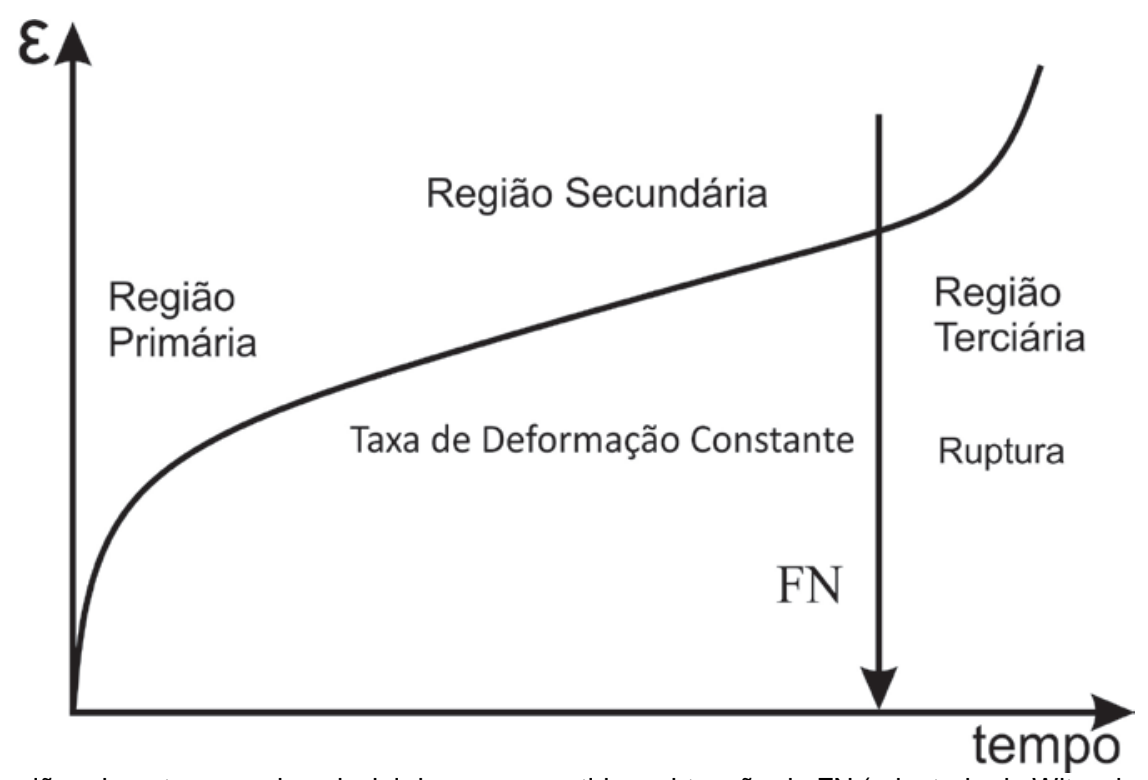

Figura 1. Regiões durante o ensaio uniaxial de carga repetida e obtenção do FN (adaptada de Witczak et al., 2002).

Tabela 1. Critérios de FN para diferentes níveis de tráfego

\begin{tabular}{|c|c|c|c|c|c|c|c|}
\hline \multirow{2}{*}{$\begin{array}{l}\text { Pesquisas / } \\
\text { Níveis de Tráfego } \\
\text { (número N) }\end{array}$} & \multirow[t]{2}{*}{$\begin{array}{l}V v \\
(\%)\end{array}$} & \multirow[t]{2}{*}{$\begin{array}{l}\text { Temp. } \\
\left({ }^{\circ} \mathrm{C}\right)\end{array}$} & \multirow{2}{*}{$\begin{array}{l}\text { Tensão } \\
\text { Axial } \\
(\mathrm{kPa}) \\
\end{array}$} & \multirow{2}{*}{$\begin{array}{c}\text { Leve } \\
<3 \times 10^{6} \\
\end{array}$} & Médio & Pesado & \multirow{2}{*}{$\begin{array}{l}\begin{array}{l}\text { Extremamente } \\
\text { Pesado }\end{array} \\
>3 \times 10^{7} \\
\end{array}$} \\
\hline & & & & & {$\left[3 \times 10^{6} ; 1 \times 10^{7}\right]$} & {$\left[1 \times 10^{7} ; 3 \times 10^{7}\right]$} & \\
\hline Nascimento (2008) & $7,0 \pm 0,5$ & 60,0 & 204 & - & 300 & 750 & - \\
\hline $\begin{array}{l}\text { Advanced Asphalt } \\
\text { Technologies (2011) }\end{array}$ & 4,$7 ; 8,2$ & 31,$3 ; 54,3$ & 600 & - & 53 & 190 & 740 \\
\hline Bonaquist (2012) & 6,$0 ; 7,3$ & 49,6 & 600 & 15 & 50 & 135 & 415 \\
\hline
\end{tabular}

Ademais, Choi (2013) simplificou o modelo de deformação permanente (Equação 1) denominado Shift Model, desenvolvido por Subramanian (2011), que tem como principal objetivo representar tanto a região da zona primária quanto a zona secundária. Esse modelo utiliza os dados do ensaio TSS. E o ensaio permite avaliar a mistura a partir da condição de confinamento sob diferentes combinações de temperatura e tensão desvio, período de repouso e carregamento. A análise desse modelo é baseada em princípios viscoplásticos. As propriedades obtidas passam a representar, à luz da mecânica dos materiais, os fenômenos que de fato ocorrem em campo, o que contribui para formulação de projetos rodoviários menos empíricos, e mais mecanicistas.

$\varepsilon_{v p}=\frac{A+B \cdot N}{(C+N)^{\alpha}}$

O expoente ( $\alpha$ ) é a inclinação da curva da zona secundária na escala log-log. Esta inclinação representa o endurecimento do material. Altos valores de $\alpha$ indicam baixas inclinações, assim as deformações permanentes se desenvolvem lentamente. O parâmetro $B$ determina o nível de deformação permanente juntamente com o valor de $\alpha$. O parâmetro A contribui para o desenvolvimento inicial de deformação, e $C$ determina a forma de curvatura e em qual ponto a curvatura começará. Logo, $A$ e $C$ governam a forma de desenvolvimento da deformação, assim como o seu início na hora do ensaio. Quando o $N$ for pequeno, $A$ e $C$ têm um grande efeito sobre a evolução da deformação permanente. $A, B$ e $C$ também podem ser expressos em função do tempo de carregamento, pela tensão desvio e período de repouso (Choi, 2013).
Choi (2013) comenta que o principal objetivo da utilização do Shift Model e do protocolo de ensaio é prever a deformação permanente nas camadas de pavimentos asfálticos. Para tanto, o Shift Model foi implementado no programa LVECD, desenvolvido na Universidade Estadual da Carolina do Norte (NCSU), Estados Unidos.

\subsubsection{Tensões no ensaio triaxial}

Há várias recomendações para representar o estado de tensão para avaliação da deformação permanente. A maioria dos pesquisadores concorda com a necessidade de converter o estado de tensões in situ para os estados de tensões experimentais. No entanto, há discordância significativa em relação ao estado de tensão que deve ser adotado nos ensaios.

O estudo realizado em NCHRP e relatado no Report 465 - Simple Performance Test for Superpave Mix Design (Witczak et al., 2002) indicou o nível de tensão desvio entre 483 a $966 \mathrm{kPa}$ (70 a 140psi) para o ensaio confinado. Nesse estudo a pressão confinante assumiu valores entre 35 a 207kPa (5 a 30psi).

Gibson (2006) apresentou um método para avaliar a presença da tensão de confinamento e tensão desvio nas estruturas do pavimento. O método consiste em duas etapas de análise numérica. Na primeira etapa é realizada uma análise elástica das camadas por meio do software KENLAYER para calcular a distribuição de tensões em uma estrutura simples do pavimento e obter as tensões de confinamento (Equação 2) e desvio (Equação 3). Alguns investigadores indicaram o conceito de invariante de tensão (Gibson et al., 2009; Hajj et al., 2010) para quantificar a presença dessas tensões nas estruturas do pavimento. 


$$
\begin{gathered}
\sigma_{c}=\frac{I_{1}}{3}=\left(\frac{\sigma_{1}+\sigma_{2}+\sigma_{3}}{3}\right) \\
\sigma_{d}=\frac{1}{\sqrt{2}} \sqrt{\left(\sigma_{1}-\sigma_{2}\right)^{2}+\left(\sigma_{2}-\sigma_{3}\right)^{2}+\left(\sigma_{3}-\sigma_{1}\right)^{2}}
\end{gathered}
$$

Onde: $\sigma_{\mathrm{c}}$ - Tensão de confinamento; $I_{1}$ - Primeiro invariante do tensor de tensões; $\sigma_{1}, \sigma_{2}$ e $\sigma_{3}$ - Tensões principais; $\sigma_{\mathrm{d}}$ - Tensão desvio: $\sigma_{d}=\frac{3}{\sqrt{2}} \tau_{\text {oct }}$. A tensão de cisalhamento octaédrica $\left(\tau_{\text {oct }}\right)$ pode ser escrita em função do segundo invariante do tensor desviador de tensão $\left(J_{2}\right)$ : $\tau_{\text {oct }}=\sqrt{\frac{2}{3} J_{2}}$. Já $\quad J_{2} \quad$ é $\quad$ obtido por $J_{2}=\frac{1}{6}\left(\sigma_{1}-\sigma_{2}\right)^{2}+\left(\sigma_{2}-\sigma_{3}\right)^{2}+\left(\sigma_{3}-\sigma_{1}\right)^{2}$.

Na segunda etapa, a distribuição de tensões é combinada com um modelo viscoplástico tridimensional, aprimorado por Gibson (2006) (Equação 4), com base em um critério de escoamento de HiSS (Hierarchal Single Surface) simplificado, utilizando a regra de fluxo de Perzyna. Ao aplicar o princípio (t-TS) tempo-temperatura, esta regra incorpora a dependência da temperatura.

$$
\frac{d \varepsilon_{i j}^{v p}}{d t_{R}}=\Gamma f(F) \frac{\partial F}{\partial \sigma_{i j}}
$$

Onde: - Taxa de deformação na direção ij prevista. redução do tempo é dada por: $t_{R}=\frac{t}{a(T)} ; \frac{d \varepsilon_{i j}^{v p}}{d t_{R}} t$ -

Tempo reduzido. O princípio t-TS reduz o número de ensaios necessários para a calibração e ampliação da faixa aplicável do modelo proposto também. $\Gamma$ - Constante da viscosidade-tipo; $f(F)$ - Função da superfície de escoamento com endurecimento, dada por:

$F=J_{2}-\left[\gamma\left(I_{1}+R(\xi)\right)^{2}+\alpha(\xi)\left(I_{1}+R(\xi)\right)^{n}\right]$. Onde: $\xi=\varepsilon_{1}^{\mathrm{VP}}(t)+\varepsilon_{2}^{\mathrm{VP}}(t)+\varepsilon_{3}^{\mathrm{VP}}(t)$, sendo $\xi$ : deformação viscoplástica volumétrica; $\varepsilon_{1}^{\mathrm{VP}}(t), \varepsilon_{2}^{\mathrm{VP}}(t)$ e $\varepsilon_{3}^{\mathrm{VP}}(t)$ : deformações viscoplásticas no eixo $\mathrm{x}$, y e z, respetivamente. A trajetória da deformação viscoplástica, que é a deformação viscoplástica volumétrica, é usada como uma variável de estado interno de endurecimento. A deformação volumétrica é um indicador da história de deformação bem como o estado atual de endurecimento. Os parâmetros $\gamma$ e n são fixos e governam o tamanho e a forma da superfície de escoamento crescente (constante); $\alpha(\xi)=$ : parâmetro de endurecimento (função da deformação viscoplástica); $R(\xi)$ $=R_{0}+R_{A} \xi^{k_{2}}$ : resistência à tração do material quando a tensão desvio é igual a zero; $k_{1}$ e $k_{2}$ - são constantes dos modelos.

Gibson et al. (2009) sugeriram alterar a obtenção da deformação viscoplástica volumétrica $(\xi)$, calculando-a em função da deformação axial e radial: $\xi=\sqrt{\left(\varepsilon_{\text {axial }}\right)^{2}+2\left(\varepsilon_{\text {radial }}\right)^{2}} \cdot \alpha_{0} e^{k_{1} \xi}$
Gibson et al. (2009) reconhecem que imprecisões são inevitáveis, tendo em vista o uso misto de teoria da elasticidade linear para fornecer tensões para viscoplasticidade não linear, e encorajam a modelagem por elementos finitos, tendo viscoplasticidade integrada com elasticidade (ou viscoelasticidade). Baseado no encorajamento de Gibson et al. (2009), Carvalho (2012) implementou e calibrou o avançado modelo viscoplástico tridimensional (Gibson, 2006) em um software comercial de elementos finitos 3D. Esse trabalho resultou no desenvolvimento de novas funções de transferência para potencial incorporação no MechanisticEmpirical Pavement Desing Guide (MEPDG).

Gibson et al. (2009) salientam que as tensões exploradas são estimativas. No entanto, os autores também destacam que a região de interesse, a uma profundidade sob a borda do pneu está de acordo com a literatura (Monismith et al., 2006). O local crítico para deformação permanente está identificado pela localização da região volumétrica de maior deformação viscoplástica. A Figura 2 mostra as áreas críticas encontradas no limite exterior do carregamento da roda, e a uma profundidade aproximadamente igual à zona do bulbo de cisalhamento da estrutura. Nas áreas críticas o estado de tensão encontrado corresponde a uma pressão de confinamento de $69 \mathrm{kPa}$ (10psi) e uma tensão desvio de $518 \mathrm{kPa}$ (75psi) (Gibson et al., 2009). Baseado nessa pesquisa, Choi (2013) adotou, no protocolo de ensaio TSS, as tensões desvios de 483 (70psi), 689 (100psi) e 896kPa (130psi) e de confinamento de $69 \mathrm{kPa}(10 \mathrm{psi})$.

Hajj et al. (2010), depois da realização de várias simulações considerando a presença ou ausência de frenagem, verificaram que a tensão de confinamento variou de 186 (27psi) a 324kPa (47psi) e a tensão desvio variou de 476 (69psi) a $910 \mathrm{kPa}(132 \mathrm{psi})$. Essas diferenças se traduzem em um aumento da tensão desvio de aproximadamente $40 \%$ e um aumento da tensão de confinamento em cerca de $5 \%$.

Von Quintus et al. (2012) sugeriram o uso de uma tensão desvio de $483 \mathrm{kPa}$ (70psi) associada a uma tensão de confinamento de $69 \mathrm{kPa}$ (10psi). A partir dos resultados dos ensaios os autores mostraram que a deformação permanente diminui ligeiramente para confinamentos acima de $69 \mathrm{kPa}$. Os autores selecionaram a tensão desvio, com base em resultados de ensaio, de $207 \mathrm{kPa}$ (30psi) e 345kPa (50psi), para o caso não confinado, e de $483 \mathrm{kPa}$ (70psi) para o caso de um confinamento de $69 \mathrm{kPa}(10 \mathrm{psi})$. Esses autores selecionaram $483 \mathrm{kPa}$ porque esta era a maior tensão desvio ou normal perto da superfície do pavimento. A pesquisa não incluiu vários níveis de tensão desvio porque os autores acreditavam que a partir de 345 e $483 \mathrm{kPa}$ ocorria um pequeno grau de não linearidade. Esta suposição é importante porque o objetivo do estudo foi calibrar o modelo de deformação permanente do MEPDG, que assume proporcionalidade linear entre a deformação permanente e a tensão desvio. Os autores destacam que $345 \mathrm{kPa}$ (50psi) com um confinamento de $69 \mathrm{kPa}$ (10psi) também poderia ser utilizado, sem reduzir a qualidade dos dados. 


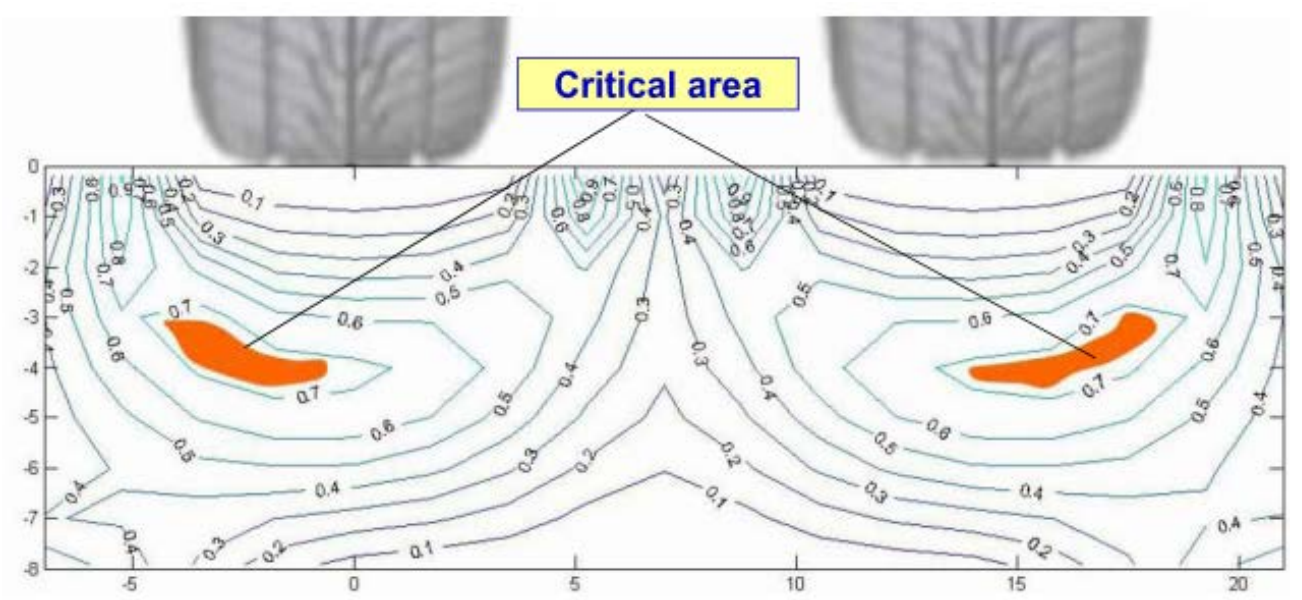

Figura 2. Áreas críticas da deformação viscoplástica (Gibson et al., 2009).

Tabela 2. Comparação entre o ensaio uniaxial de carga repetida e o TSS.

\begin{tabular}{|c|c|}
\hline 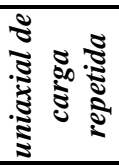 & $\begin{array}{l}\text { - Aplicação de pulsos de carga ao CP, a uma determinada frequência }(1 \mathrm{~Hz}) \text {, tempo de aplicação de carga (0,1s) e in- } \\
\text { tervalo entre as aplicações das cargas }(0,9 \mathrm{~s}) \text {, a uma temperatura especificada }\left(60^{\circ} \mathrm{C}\right) \text {. A tensão aplicada em cada } \\
\text { ciclo é de } 204 \mathrm{kPa} \text { no período de } 0,1 \mathrm{~s} \text { e de } 10,2 \mathrm{kPa} \text { durante os } 0,9 \mathrm{~s} \text { de repouso. } \\
\text { - Número máximo de } 10.000 \text { ciclos. }\end{array}$ \\
\hline 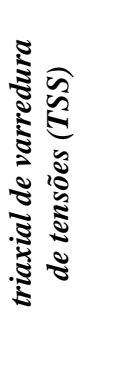 & $\begin{array}{l}\text { - Ensaio de referência (TRLPD): tensão aplicada de } 689 \mathrm{kPa} \text { (100psi) no período de } 0,4 \mathrm{~s} \text { e de } 35 \mathrm{kPa} \text { (5psi) durante os } \\
\text { 10s de repouso a uma temperatura de } 47^{\circ} \mathrm{C} \text { (máxima) e número de ciclos igual a } 600 \text {. } \\
\text { - Ensaios Múltiplos de Varredura de Tensões (MSS): aplicação de pulsos de carga ao CP, tempo de aplicação de } \\
\text { carga }(0,4 \mathrm{~s}) \text { e intervalo entre as aplicações das cargas de } 1,6 \mathrm{~s} \text {, a temperaturas baixa (TL) e intermediária (TI) (17 e } \\
\left.37^{\circ} \mathrm{C}\right) \text { e tempo de aplicação de carga }(0,4 \mathrm{~s}) \text { e intervalo entre as aplicações das cargas de } 10 \mathrm{~s} \text { a temperatura alta (TH) } \\
\text { de } 47^{\circ} \mathrm{C} \text {. Para cada temperatura a aplicação de ciclos igual a } 200 \text {. } \\
\text { - Três níveis de tensões são aplicados em cada temperatura: } 483,689 \text { e } 896 \mathrm{kPa} \text { no período de } 0,4 \mathrm{~s} \text {. Durante o período } \\
\text { de repouso é aplicado } 5 \% \text { de carga atuante. Assim, durante o repouso são aplicadas, respectivamente, as tensões de } \\
\text { 24, } 35 \text { e } 45 \mathrm{kPa} \text {. }\end{array}$ \\
\hline
\end{tabular}

\subsection{Comparação entre os Ensaios Uniaxial e Triaxial}

Apesar de o ensaio TSS representar melhor a deformação permanente em campo, no Brasil, o ensaio uniaxial de carga repetida é utilizado frequentemente para ranquear as misturas asfálticas com relação à resistência à deformação permanente (Nascimento, 2008; Onofre, 2012; Borges, 2014; Pazos, 2015). No âmbito internacional, encontra-se em avaliação a especificação norte-americana, AASHTO TP (2013) - Determining the Rutting Parameters of Asphalt Concrete from Triaxial Stress Sweep (TSS) Tests, para a análise de deformação permanente de misturas asfálticas em laboratório. A Tabela 2 apresenta uma comparação entre as características do ensaio uniaxial de carga repetida e o (TSS).

No ensaio TSS, inicialmente são realizados os ensaios TRLPD do qual é possível obter a curva de referência. O critério de parada deste ensaio é o de 600 ciclos de carregamento. Assim, pode-se dizer que as misturas devam atingir esse ciclo de carregamento na curva de referência sem a ruptura, para a aplicação completa do Shift Model. Quando a mistura não atende a este critério mínimo, os ensaios MSS não são realizados, por motivo do surgimento da zona terciária, o qual não permite a calibração do modelo.

\section{MATERIAIS E MÉTODOS}

\subsection{Laboratório}

Tendo em vista os objetivos propostos para esta pesquisa, a metodologia empregada consistiu, inicialmente, na caracterização dos ligantes e agregados. Em seguida, reproduziram-se as dosagens de misturas asfálticas aplicadas nos trechos monitorados, utilizando os compactadores Marshall para a mistura DNIT/CE e Superpave (CGS) para a mistura CCR/SP.

Foram utilizados dois ligantes asfálticos: CAP 30/45 Replan (PG 70-caracterizado apenas no limite superior) e CAP 50/70 Lubnor (também PG 70) de acordo com as especificações brasileiras (ANP, 2005) e norte americana Superpave, conforme ensaios listados a seguir: (i) Grau de desempenho (PG) (ASTM D6373, 2007); (ii) Penetração (PEN) a $25^{\circ} \mathrm{C}, 100 \mathrm{~g}, 5 \mathrm{~s}$ (ASTM D5, 2006); (iii) Ponto de amolecimento (PA) (ASTM D36, 2009) e (iv) Viscosidade rotacional a 135,150 e $177^{\circ} \mathrm{C}$ (ASTM D4402, 2007). A Tabela 3 resume os resultados da caracterização dos ligantes.

Constatou-se por meio dos ensaios empíricos que para os dois ligantes investigados, a penetração, o ponto de amolecimento e a susceptibilidade térmica dos mesmos foram adequadas aos limites estabelecidos pela Agência Nacional do Petróleo Gás Natural e Biocombustíveis (ANP). Os resultados do CAP 30/45, utilizado na mistura CCR/SP, apresentaram maior valor de $\mathrm{PA}\left(54^{\circ} \mathrm{C}\right)$ e menor valor de 
Tabela 3. Caracterização dos ligantes asfálticos

\begin{tabular}{|c|c|c|c|c|}
\hline Propriedade ou parâmetro & CAP 30/45 & $\begin{array}{l}\text { Limites CAP } \\
30 / 45\end{array}$ & CAP 50/70 & $\begin{array}{l}\text { Limites CAP } \\
50 / 70\end{array}$ \\
\hline Penetração a $25^{\circ} \mathrm{C}$ - PEN (dmm) & 44 & 30 a 45 & 59 & 50 a 70 \\
\hline Ponto de amolecimento - PA $\left({ }^{\circ} \mathrm{C}\right)$ & 54 & Mín. 52 & 50 & Mín. 46 \\
\hline Índice de susceptibilidade térmica & $-1,2$ & $-1,5 \mathrm{a}+0,7$ & $-0,8$ & $-1,5 a+0,7$ \\
\hline Viscosidade Brookfield $135^{\circ} \mathrm{C}$-sp21 20rpm (cP) & 548 & Mín. 374 & 657 & Mín. 274 \\
\hline Faixa de temperatura usinagem $\left({ }^{\circ} \mathrm{C}\right)$ & 158 a 165 & Máx 177 & 163 а 170 & Má \\
\hline Faixa de temperatura compactação $\left({ }^{\circ} \mathrm{C}\right)$ & 146 а 150 & мах.1/7 & 150 а 155 & Мах. 1// \\
\hline
\end{tabular}

Tabela 4. Caracterização dos agregados

\begin{tabular}{|c|c|c|c|c|c|c|c|c|c|}
\hline \multirow[b]{2}{*}{ Ensaios } & \multicolumn{5}{|c|}{$\mathrm{DNIT} / \mathrm{CE}$} & \multicolumn{4}{|c|}{ CCR/SP } \\
\hline & $3 / 4^{\prime \prime}$ & $1 / 2 "$ & $\begin{array}{l}\text { Areia } \\
\text { Rio }\end{array}$ & $\begin{array}{l}\text { Areia } \\
\text { Campo }\end{array}$ & Fíler & $3 / 4^{\prime \prime}$ & $3 / 8^{\prime \prime}$ & $\begin{array}{l}\text { Pó de } \\
\text { Pedra }\end{array}$ & Fíler \\
\hline Densidade Real & 2,716 & 2,706 & 2,560 & 2,574 & 2,740 & 2,653 & 2,667 & 2,688 & 2,450 \\
\hline Densidade Aparente & 2,654 & 2,635 & - & - & - & 2,625 & 2,627 & 2,659 & - \\
\hline Absorção (\%) & 0,85 & 0,99 & - & - & - & 0,50 & 0,70 & 0,50 & - \\
\hline Abrasão Los Angeles (\%) & 35,2 & 35,5 & - & - & - & 34,9 & - & & - \\
\hline Equivalente de areia (\%) & - & - & 95,2 & 41,6 & - & - & - & 58,1 & - \\
\hline Adesividade & Satis. & Satis. & - & - & - & Satis. & - & - & - \\
\hline
\end{tabular}

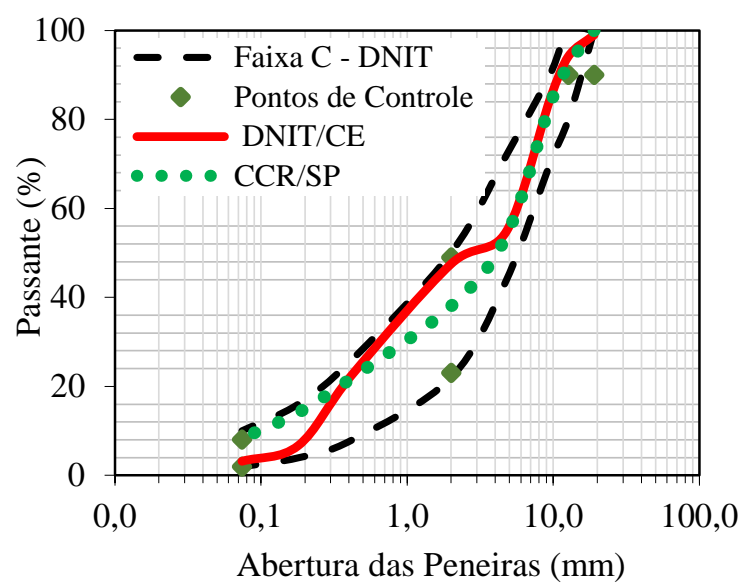

Figura 3. Curvas granulométricas das misturas do DNIT/CE e CCR/SP

PEN (44dmm), indicando uma menor susceptibilidade à deformação permanente.

Para a determinação das faixas de temperatura de usinagem e de compactação das misturas, foi feito o ensaio de viscosidade Brookfield nos ligantes asfálticos utilizados. Essas faixas de temperatura são encontradas a partir de faixas de viscosidade adequadas para as quais os ligantes asfálticos tornam as mistura trabalháveis [faixa de usinagem de 0,15 a 0,19Pa.s $(0,17 \pm 0,02$ Pa.s)] e compactáveis [faixa de compactação de 0,25 a 0,31Pa.s (0,28 \pm 0,03Pa.s)]. Percebe-se da Tabela 3 que as faixas de temperatura de usinagem e compactação dos dois CAPs atendem a especificação de serviço 031/06 do DNIT (limite de $177^{\circ} \mathrm{C}$ ).

Os agregados utilizados para compor as misturas asfálticas da pesquisa são provenientes de dois estados brasileiros: Ceará (pedreira Pyla), utilizado na mistura DNIT/CE, e São Paulo (pedreira Jambeiro), utilizado na mistura CCR/SP, sendo os dois agregados do tipo gnáissico. Os agregados foram submetidos aos diversos tipos de ensaios de caracterização preconizados pelo DNIT para a obtenção das suas propriedades físicas e mecânicas: (i) granulometria (DNER-ME 83/98), (ii) abrasão Los Angeles (DNER-ME 35/98), (iii) densidade do agregado miúdo (DNER-ME 84/95), (iv) absorção e densidade do agregado graúdo (DNER-ME 81/98) e (v) adesividade (DNER-ME 78/94). A Figura 3 apresenta os resultados das granulometrias e a Tabela 4 exibe as propriedades dos agregados.
A composição granulométrica é uma das variáveis que influencia na resistência à deformação permanente. A curva de projeto da mistura do DNIT/CE contém 21\% de brita 3/4", $35 \%$ de brita $1 / 2$ ”, $22 \%$ de areia de rio, $20 \%$ de areia de campo e $2 \%$ de Cal hidratada do tipo $\mathrm{CH}-1$. Essa mistura apresenta uma curva com degrau, uma vez que apresentou uma descontinuidade em sua faixa, a partir da peneira $\mathrm{N}^{\circ} 10(2,00 \mathrm{~mm})$, e isso sugere pequena porcentagem de agregados com tamanho intermediário, formando um patamar na curva granulométrica correspondente às frações intermediárias. Além disso, a curva DNIT/CE apresentou comportamento próximo ao limite superior da Faixa $\mathrm{C}$ do DNIT até a peneira $\mathrm{N}^{\circ} 10$, caracterizando maior quantidade de miúdos. A curva de projeto da mistura CCR/SP contém $25 \%$ de brita 3/4", 25\% de brita 3/8”, 48,5\% de póde-pedra e 1,5\% de Cal hidratada do tipo $\mathrm{CH}-1$. A mistura CCR/SP é composta por uma curva granulométrica bem distribuída e contínua. As propriedades mecânicas de misturas asfálticas são relacionadas ao esqueleto granular e ao tipo e teor de ligante, bem como a interação entre eles. Observando apenas a granulometria, espera-se que a mistura da CCR/SP apresente resistência à deformação permanente superior a mistura DNIT/CE.

Quanto à dosagem, a mistura utilizada no trecho da CCR foi dosada pela metodologia Superpave com o N JETO, para um volume de tráfego de médio a alto, igual a 100 giros. A mistura utilizada no trecho do DNIT foi dosada de acordo com a metodologia Marshall (75 golpes por face do 
Tabela 5. Resultados das dosagens

\begin{tabular}{clllllll}
\hline \multirow{2}{*}{ Mistura } & \multirow{2}{*}{ Origem } & $\begin{array}{l}\text { Metodologia } \\
\text { de dosagem }\end{array}$ & $\begin{array}{l}\text { Teor de } \\
\text { CAP (\%) }\end{array}$ & TMN (mm) & $\begin{array}{l}\text { Vvde } \\
\text { projeto (\%) }\end{array}$ & $\begin{array}{l}\text { DMT } \\
\text { (calculada) }\end{array}$ & $\begin{array}{l}\text { Gmm } \\
\text { (medida) }\end{array}$ \\
\hline 1 & DNIT/CE & Marshall & 5,8 & 12,5 & 4,2 & 2,423 & - \\
2 & CCR/SP & Superpave & 4,7 & 12,5 & 4,0 & - & 2,478 \\
\hline
\end{tabular}

CP para a determinação do teor de projeto) preconizada no Brasil (DNER - ME 043/95). Para a confecção dos CPs, o CAP 50/70 foi aquecido a $165^{\circ} \mathrm{C}$ e os agregados a $175^{\circ} \mathrm{C}$. Nessa mistura foi utilizado um aditivo melhorador de adesividade, DOPE, em 0,3\% em massa do ligante. No caso do CAP $30 / 45$, este foi aquecido a $152^{\circ} \mathrm{C}$ e os agregados a $162^{\circ} \mathrm{C}$. Essa mistura foi envelhecida por duas horas em estufa a $145^{\circ} \mathrm{C}$.

A Tabela 5 exibe os resultados das dosagens. Para realização dos ensaios uniaxiais de carga repetida e o TSS, os CPs foram moldados com um Vv de $5,5 \% \pm 0,5$, independente do $\mathrm{Vv}$ de projeto da mistura. Ou seja, mesmo no caso de misturas densas com $V_{v}=4,0 \%$, é comum o uso de teores de 5,5 a 7,0\% de Vv para o ensaio de deformação permanente, de modo a produzir a mistura em sua condição crítica no começo do serviço, antes de qualquer adensamento causado pelo tráfego inicial. O Vv de 5,5\% $\pm 0,5$ vem sendo adotado em grupos de pesquisa no Brasil (Martins, 2014; Borges, 2014) e no mundo (Choi, 2013; LaCroix, 2013). A justificativa deste valor está relacionada ao número médio do $\mathrm{Vv}$ que o revestimento atinge ao longo da vida de serviço.

Foram realizados os ensaios de referência (TRLPD) e o uniaxial de carga repetida. Para isso utilizou-se a UTM - 25 (Universal Testing Machine - 25) do Laboratório de Mecânica dos Pavimentos da Universidade Federal do Ceará (UFC), que é uma máquina de célula triaxial. As pressões de confinamento são originadas por meio de um compressor a ar. O software UTS 030 foi usado para a programação da máquina (controle de temperatura, tensões atuantes, pressão de confinamento, período de repouso e carregamento, número de ciclos, etc) e aquisição de dados mediante os ensaios. As amostras foram preparadas para ensaios confinados e receberam uma membrana de látex a fim de uniformizar a pressão confinante, pois esta membrana tem a finalidade de evitar a absorção de ar pela amostra. As leituras de deslocamentos foram realizadas por dois LVDTs (Linear Variable Differential Transformers) acoplados na câmara de confinamento. Borges (2014) detalhou todas as etapas de montagem, assim como a etapa de pré-condicionamento desse ensaio. A etapa seguinte do protocolo é o ensaio de referência. Nessa etapa assume-se um único nível de tensão desvio $(689 \mathrm{kPa})$ a $69 \mathrm{kPa}$ de confinamento, assim como tempo de carregamento $(0,4 \mathrm{~s})$, período de repouso (10s) e temperatura $\left(47^{\circ} \mathrm{C}\right)$.

O procedimento do ensaio TSS é composto por seis etapas: (1) preparação do CP; (2) condicionamento da temperatura alvo na câmara da UTM - 25; (3) instalação do CP na UTM - 25; (4) pressurização e correção da temperatura alvo, caso seja necessário; (5) ensaio fingerprint e (6) realização dos ensaios de referência e MSS. Para aplicação do protocolo de ensaio foram moldados 12 CPs para cada mistura (DNIT/CE e CCR/SP): 3 para o ensaio TRLPD e mais 9 para os ensaios MSS, sendo que são 3 CPs para cada tem- peratura. Foram fabricados 3 CPs adicionais para cada mistura para a realização do ensaio uniaxial de carga repetida, totalizando 15 CPs por mistura investigada.

\subsection{Campo}

Esta pesquisa abrange dois trechos monitorados. O trecho 1, recém reconstruído, foi viabilizado junto ao DNIT/CE e faz parte dos serviços de adequação de capacidade e restauração da rodovia BR-222. Essa é uma via de ligação entre Sobral, $4^{\mathrm{a}}$ maior economia do Estado, e a capital cearense, Fortaleza. O projeto inteiro consiste de um trecho maior, entre o km 64 e o km 122, e está localizado entre os municípios de Croatá-CE e Itapajé-CE, onde foram investidos R\$ 89,8 milhões. O trecho monitorado pela UFC e incluído nesta pesquisa consta de $300 \mathrm{~m}$, que se inicia no km 109,7 (Itapajé-CE). Nessa via localiza-se o trecho que ficou popularmente conhecido como "Curva da Morte", em função dos vários acidentes. Os serviços de adequação de capacidade e restauração da rodovia nesse trecho objetivaram a transformação da curva em uma reta, de modo a reduzir os riscos de acidentes.

O trecho 1 foi submetido a medições, nos meses 4 e 7, de flecha em trilha de roda com treliça metálica, com base de 1,2m (DNIT-PRO 006/03). Os ensaios foram realizados nos dois sentidos do trecho. Mas optou-se por selecionar a faixa externa de rolamento do sentido Itapajé-Umirim por se tratar do ponto mais crítico.

O Trecho 2 é um trecho da rodovia Presidente Dutra (BR-116), que foi viabilizado junto à CCR NovaDutra. Essa via faz ligação entre as cidades do Rio de Janeiro e São Paulo e é considerada uma das mais importantes rodovias do Brasil, atravessando uma região na qual se transporta uma parcela considerável (50\%) do PIB (Produto Interno Bruto) do país (Euromoney Institutional Investor Company - EMIS, 2015). O trecho monitorado 2, incluído nesta pesquisa, é o da Marginal Sul km 227,7 (Guarulhos-SP), que teve a mistura asfáltica, investigada nesta pesquisa, aplicada há 3,5 anos.

Esse trecho foi avaliado pelo Sistema de Visualização do Pavimento em 3D (SCAN VIAS 3D), através de sensores a laser e imagens da superfície do pavimento. Esse equipamento possui resolução de $1 \mathrm{~mm}$ em qualquer direção e atende ao DNIT-PRO 006/03. Serigos et al. (2012) apresentaram resultados comparáveis de afundamento em trilha de roda utilizando sensores a laser e réguas, que trazem vantagens ao eliminar a subjetividade do operador e ao possibilitar levantamentos de forma mais rápida e segura, tanto para os operadores como para os usuários da via.

\section{APRESENTAÇÃO E ANÁLISE DOS RESULTADOS}

\subsection{Laboratório}

O ensaio TRLPD, parte integrante do protocolo de ensaio TSS, e o ensaio uniaxial de carga repetida foram TRANSPORTES v. 23, n. 2 (2015), p. 44-55 
Tabela 6. Resultados dos ensaios de deformação permanente.

\begin{tabular}{|c|c|c|c|c|c|c|c|c|}
\hline \multicolumn{4}{|l|}{ TRLPD } & & \multicolumn{4}{|l|}{$T R L P D$} \\
\hline$n^{\circ} C P$ & $F N$ & $\varepsilon$ total (\%) & $V v(\%)$ & & $n^{\circ} C P$ & $F N$ & $\varepsilon$ total (\%) & $V v(\%)$ \\
\hline CP1 & 26 & 3,249 & 5,4 & & CP1 & 191 & 1,891 & 6,0 \\
\hline CP2 & 34 & 3,067 & 5,6 & & CP2 & 199 & 1,468 & 5,7 \\
\hline Média & 30 & 3,158 & 5,5 & & Média & 195 & 1,680 & 5,9 \\
\hline$\sigma$ & 5,7 & 0,129 & 0,1 & \multirow{3}{*}{ 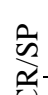 } & $\sigma$ & 5,7 & 0,299 & 0,5 \\
\hline $\mathrm{CV}(\%)^{*}$ & 18,9 & 4,1 & 2,6 & & CV $(\%)^{*}$ & 2,9 & 17,8 & 8,8 \\
\hline \multicolumn{4}{|c|}{ uniaxial de carga repetida } & & \multicolumn{4}{|c|}{ uniaxial de carga repetida } \\
\hline$n^{o} C P$ & $F N$ & $\varepsilon$ total $(\%)$ & $V v(\%)$ & & $n^{\circ} C P$ & $F N$ & $\varepsilon$ total $(\%)$ & $V v(\%)$ \\
\hline CP1 & 45 & 2,026 & 5,4 & & $\mathrm{CP} 1$ & 1173 & 1,268 & 5,1 \\
\hline $\mathrm{CP} 2$ & 47 & 1,873 & 5,7 & & $\mathrm{CP} 2$ & 1261 & 1,275 & 5,4 \\
\hline Média & 46 & 1,950 & 5,6 & & Média & 1217 & 1,272 & 5,3 \\
\hline$\sigma$ & 1,4 & 0,108 & 0,2 & & $\sigma$ & 62,2 & 0,005 & 0,2 \\
\hline CV (\%)* & 3,1 & 5,5 & 3,8 & & CV (\%)* & 5,1 & 0,4 & 4,0 \\
\hline
\end{tabular}

*Mesmo cientes da limitação do número de CPs, os autores optaram por registrar este parâmetro..

aplicados nas duas misturas deste trabalho, e dessa forma foi possível avaliar a resistência à deformação permanente, considerando o FN e o nível de deformação alcançado em cada ensaio. Vale lembrar que esses dois ensaios são realizados sob condições bastante diferentes, como mostrado na Tabela 2.

As misturas foram ensaiadas até a obtenção da taxa mínima de deformação plástica, onde é obtido o FN. As duas misturas apresentaram rompimento antes dos 600 ciclos no ensaio de TRLPD [Figura 4(b)], impossibilitando a realização dos ensaios MSS apresentado no protocolo, assim como rompimento antes dos 10.000 ciclos no ensaio uniaxial de carga repetida [Figura 4(a)]. Desses ensaios foram obtidas as curvas de número de ciclos de carga versus deformação permanente acumulada para avaliar a evolução da deformação ao longo do tempo.

Observa-se que a mistura CCR/SP apresentou o menor nível de deformação permanente nos dois ensaios investigados. A mistura DNIT/CE mostrou-se frágil quanto à deformação permanente nas duas metodologias, corroborando os resultados do ligante e do agregado. A Tabela 6 detalha os FNs, os volumes de vazios e os respectivos valores de deformação nos ensaios TRLPD e uniaxiais de carga repetida, média, desvio padrão $(\sigma)$ e coeficiente de variação (CV) de 2 CPs por mistura.

A mistura DNIT/CE apresentou FN no ciclo 46 e a mistura CCR/SP apresentou FN no ciclo 1217, ambas avaliadas pelo ensaio uniaxial de carga repetida. Dessa forma, a mistura DNIT/CE não se enquadrou em nenhum nível de tráfego sugerido por Nascimento (2008). Enquanto a mistura CCR/SP satisfez o critério de 750 ciclos para o tráfego pesado.

No ensaio TSS, os FNs desses materiais apresentaram-se no ciclo 30 e 195 para as misturas DNIT/CE e CCR/SP, respectivamente. No que diz respeito à avaliação dos níveis de deformação permanente, a mistura CCR/SP apresentou mais que cinco vezes maior resistência à deformação permanente que a mistura DNIT/CE para o mesmo ciclo de carregamento nas duas metodologias avaliadas. Como se pode observar, a mistura CCR/SP apresentou a maior resistência ao dano por acúmulo de deformação permanente, com maior FN e menor taxa de acúmulo de deformações na zona secundária para ambas as metodologias.

\subsection{Campo}

O revestimento asfáltico executado no trecho 1 (DNIT/CE) se mostrou pouco resistente a deformação permanente em trilha de roda durante o período de ensaio, com valores médios em torno de 4,5mm no quarto mês dos levantamentos e valores médios em torno de 5,1mm no sétimo mês de acompanhamento (Figura 5). O tráfego calculado em projeto para o início de abertura do tráfego foi de $1,2 \times 10^{6}$.

Vale destacar que o trecho investigado dá acesso aos caminhões que realizam o escoamento da produção agrícola do interior do Ceará em direção ao Porto do Pecém. Além disso, nesse trecho não é realizado controle do excesso de carga.

Em geral, valores de deformação permanente de até 12,5mm são admitidos (Choi, 2013; LaCroix, 2013). Este limite vem sendo adotado como critério máximo de deformação permanente tanto por grupos de pesquisa norte-americanos (por exemplo, a NCSU em suas pistas experimentais no NCAT), quanto por grupos de pesquisas nacionais (por exemplo, a Petrobras/Cenpes em suas pistas experimentais na Universidade Federal do Rio de Janeiro - UFRJ). Valores de deformação na camada asfáltica superiores a $12,5 \mathrm{~mm}$ equivalem a uma condição de falha na estrutura do pavimento, pois problemas como hidroplanagem podem ocorrer.

O trecho 1 (DNIT/CE) ultrapassou a flecha máxima de $12,5 \mathrm{~mm}$ nas estacas 11 e 12 nos primeiros 7 meses após a liberação do tráfego. Tal resultado corrobora os resultados de laboratório, indicando fragilidade quanto à resistência à deformação permanente. Esse resultado também indica a necessidade da criação de critérios para tráfego leve $\left(<3 \times 10^{6}\right)$, viabilizando nacionalmente a utilização dessas misturas para esse tipo de tráfego, equivalente ao proposto por Bonaquist (2012) em Wisconsin Highway Research Program.

Percebe-se uma redução, entre os meses 4 e 7, da flecha da estaca 12 . Tal resultado pode ser atribuído à utilização da treliça metálica, que mede apenas a flecha selecionada, e há uma certa subjetividade do operador ao selecionar o local exato para medição da flecha na trilha de roda. Outra hipótese é a diferença da temperatura do pavimento no momento da coleta. Apesar desse dado não ter sido verificado, as duas medições ocorreram em condições climáticas similares. 


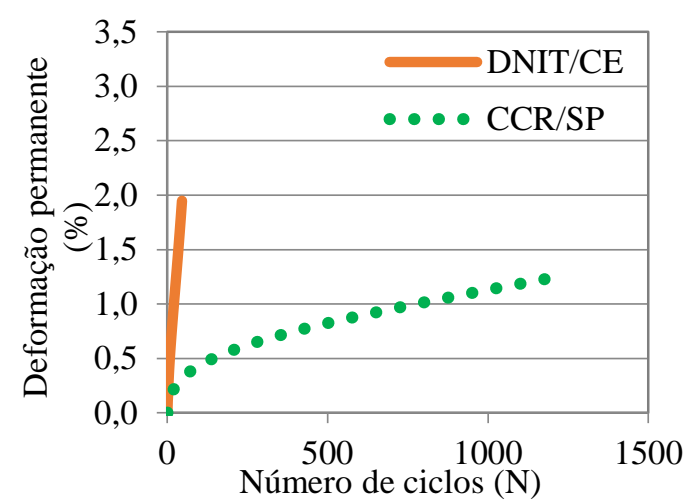

(a) uniaxial de carga repetida

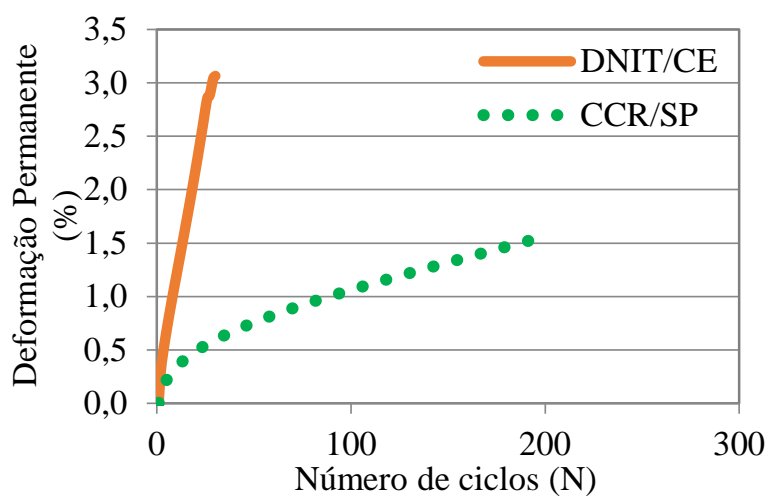

(b) TRLPD

Figura 4. Resultados das avaliações de resistência à deformação permanente: (a) uniaxial de carga repetida e (b) TRLPD

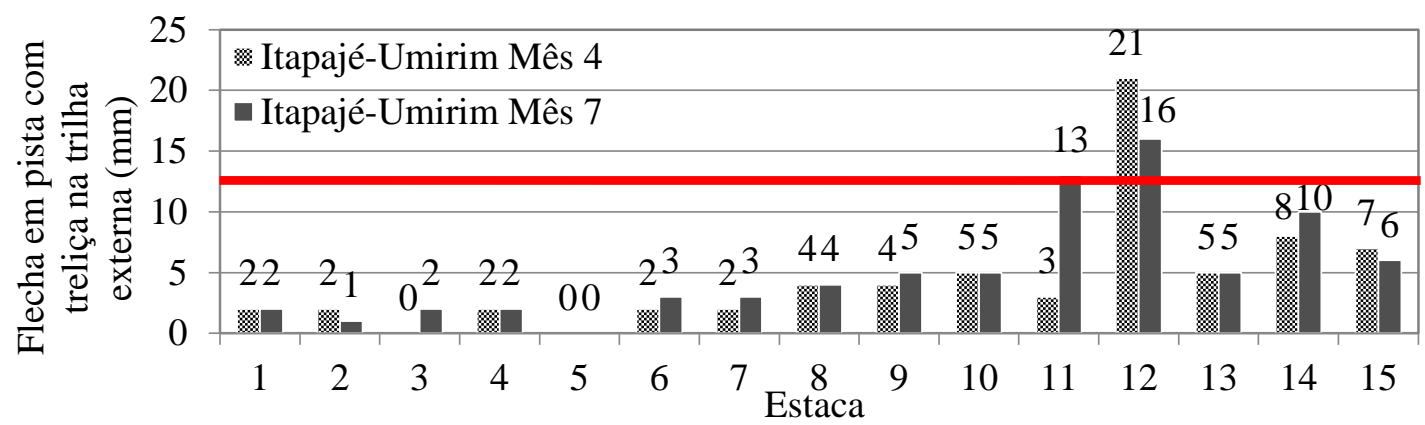

Figura 5. Flecha em trilha de roda na faixa externa de rolamento do sentido Itapajé-Umirim (DNIT/CE).

A mistura asfáltica executada no trecho 1 (DNIT/CE) apresentou precocemente problemas com afundamento em trilha de roda. Esta pesquisa apresenta alguns indícios dos fatores que contribuíram, de forma isolada e/ou em conjunto, para o surgimento precoce dessa falha, tais como: a dosagem; o emprego de ligante asfáltico com consistência inadequada à temperatura da região; distribuição granulométrica inadequada, incluindo a presença de uma porcentagem excessiva da fração miúda.

O trecho 2 (CCR/SP) apresentou até abril de 2015 (período investigado), após 3,5 anos da execução da mistura asfáltica, com o tráfego aproximado de $1,7 \times 10^{7}$, um bom desempenho em campo, com afundamento de trilha de roda inexpressivo. Esse resultado em conjunto com o resultado do ensaio uniaxial de carga repetida demonstra que o revestimento asfáltico da CCR/SP foi bem dosado e bem executado, já que apenas uma pequena consolidação foi observada. No entanto, tal resultado não condiz com o resultado do ensaio TSS, onde a mistura não atendeu o ensaio de referência, impossibilitando a previsão da evolução da falha e sugerindo fragilidade quanto à deformação permanente, no que diz respeito a este novo critério norte americano. Dessa forma, é indispensável à elaboração de pesquisa nacional visando avaliar e sugerir alterações nas condições dos ensaios TSS, no que se refere, sobretudo, aos níveis de tensão desvio e confinante, de acordo com a realidade das estruturas de pavimentos do Brasil, uma vez que essa redução pode permitir a aplicação do Shift Model e a posterior utilização do LVECD para obter as curvas de previsão da deformação permanente ao longo do tempo.

Ressalta-se que todas as conclusões restringem-se ao universo dos materiais e das metodologias utilizadas nos trechos investigados. Dessa forma, não é possível inferir que as seguintes conclusões sejam obtidas em outros tre- chos, tendo em vista a complexidade do problema que envolve controle de carga, diferenças de temperatura, diferenças na composição da estrutura (camadas e subleito), ou ainda problemas construtivos, entre outros.

\section{CONCLUSÕES E SUGESTÕES}

O presente trabalho teve como objetivo principal investigar o comportamento de misturas asfálticas quanto à deformação permanente a partir dos ensaios TSS e uniaxial de carga repetida em laboratório, associado ao monitoramento em campo por meio da verificação do afundamento de trilha de roda dos trechos da BR-222, Ceará, e da BR116, São Paulo. Dentre as conclusões da pesquisa, podemse destacar:

- Os ensaios das duas misturas investigadas, reproduzidas com as mesmas condições de pista quanto a distribuições granulométricas e teores de ligantes, mostraram a vulnerabilidade da mistura do DNIT/CE quanto à deformação permanente.

- A mistura DNIT/CE além de apresentar um degrau na curva granulométrica, apresentou também maior porcentagem de material miúdo. Assim, pode-se avaliar que o seu esqueleto mineral não apresenta um bom intertravamento, o que contribuiu para essa mistura apresentar baixa resistência à deformação permanente. O teor de CAP também contribuiu para que a mistura fosse mais susceptível à falha em questão. Vale lembrar que essa mistura foi dosada de acordo com a metodologia Marshall, que, comparada à metodologia Superpave, leva a um teor de CAP mais elevado. Lembre-se que a mistura Marshall não foi submetida ao processo de envelhecimento de duas horas. A adoção desse envelhecimento de curto prazo 
induz a uma maior absorção de ligante pelos agregados, levando a um teor de ligante ainda maior durante o procedimento de dosagem, o que poderia torná-la menos resistente à deformação permanente; por outro lado, enrijece o ligante tornando a mistura mais resistente à deformação. A mistura DNIT/CE com 5,8\% de ligante asfáltico apresentou FN no ciclo 46. A mistura CCR/SP com 4,7\% de ligante asfáltico apresentou FN no ciclo 1217. Ambas foram avaliadas pelo ensaio uniaxial de carga repetida. No ensaio TSS, os FNs desses materiais apresentaram-se no ciclo 30 e 195 para as misturas DNIT/CE e CCR/SP, respectivamente.

- Os resultados de FN para o ensaio uniaxial de carga repetida apresentaram o mesmo ranque do ensaio de TRLPD. A mesma mistura sempre obteve o maior FN e o menor nível de deformação nos ensaios uniaxial de carga repetida e TRLPD. O ensaio TRLPD apresentou menores FNs e maiores valores de deformação quando comparado ao ensaio uniaixal, ou seja, as condições do ensaio de TRLPD são mais severas. Contudo, a condição de confinamento é favorável ao intertravamento do esqueleto mineral, pois mobiliza $\mathrm{o}$ atrito interno do material.

- A mistura CCR/SP satisfez o critério de 750 ciclos para o tráfego pesado sugerido por Nascimento (2008) no ensaio uniaxial de carga repetida. No entanto, é importante a continuidade do monitoramento desse trecho para avaliar a necessidade da criação de critério para tráfegos extremamente pesados, similar ao proposto por Advanced Asphalt Technologies (2011) ou por Bonaquist (2012), indicados na Tabela 1. A mistura DNIT/CE não satisfez o critério de 300 ciclos para o tráfego médio sugerido por Nascimento (2008) nesse ensaio. Esse resultado indica a necessidade da criação de critério para tráfego leve $(<$ $3 \times 10^{6}$ ), viabilizando nacionalmente a utilização dessas misturas para esse tipo de tráfego, análogo ao proposto por Bonaquist (2012).

- Encontra-se em desenvolvimento no LMP/UFC um estudo visando avaliar e sugerir mudanças nas condições dos ensaios TSS, no que se refere principalmente aos níveis de tensão desvio e tensão confinante, uma vez que essas mudanças podem permitir a aplicação do Shift Model e a posterior utilização do LVECD para obter as curvas de simulação do desempenho do pavimento por um período de até 20 anos.

\section{AGRADECIMENTOS}

Os autores agradecem ao DNIT/CE e à CCR NovaDutra pelas informações fornecidas, ao Laboratório de Mecânica dos Pavimentos (LMP/DET/UFC) pelo apoio operacional e aos órgãos de fomento FUNCAP e CNPq pelas bolsas de pós-graduação e produtividade em pesquisa.

\section{REFERÊNCIAS}

ADVANCED ASPHALT TECHNOLOGIES, LLC (2011) A manual for design of hot mix asphalt with commentary, NCHRP Report 673, National Cooperative Highway Research Program, Washington, D.C.
ASTM (2006) ASTM D5 - Standard test method for penetration of bituminous materials. American Society for Testing and Materials. West Conshohocken.

ASTM (2007) ASTM D4402 - Standard test method for viscosity determination of asphalt at elevated temperatures using a rotational viscometer. American Society for Testing and Materials. West Conshohocken.

ASTM (2007) ASTM D6373 - Standard specification for performance graded asphalt binder. American Society for Testing and Materials. West Conshohocken.

ASTM (2009) ASTM D36 - Standard test method for softening point of bitumen (ring-and-ball apparatus). American Society for Testing and Materials. West Conshohocken.

ANP (2005) Resolução $N^{o}$. 19. Regulamento Técnico No. 3. Disponível em: <http://nxt.anp.gov.br/NXT/gateway.dll/leg/resolucoes_anp/2005/julho/ranp\%2019\%20-\%202005.xml?f=templates $\$ f n=d e-$ fault.htm\&sync=1\&vid=anp:10.1048/enu> . Acesso em: 21/02/2015.

Bernucci, L. L. B.; Motta, L. M. G.; Ceratti, J. A. P. e Soares, J. B. (2010) Pavimentação asfáltica - formação básica para engenheiros. Rio de Janeiro: Petrobras: ABEDA.

Boateng, J. A. e Maina, J. (2012) Permanent deformation testing for a new South African mechanistic pavement design method. Journal Construction and Building Materials, v. 26, pp. 541-546. DOI:

10.1016/j.conbuildmat.2011.06.055.

Bonaquist, R. (2012) Evaluation of Flow Number (FN) as a discriminating HMA mixture property. Wisconsin Highway Research Program. Projeto Número 0092-09-01.

Borges, R. L. (2014) Deformação permanente em misturas asfálticas a partir do shift model viscoplástico e ensaios triaxiais de carga repetida. Dissertação de Mestrado. Universidade Federal do Ceará, Fortaleza, CE. Disponível em: $<$ www.repositorio.ufc.br/bitstream/riufc/11168/1/ 2014_dis_rlborges.pdf $>$. Acesso em: 21/02/2015.

Carvalho, R. L. E. (2012) Prediction of permanent deformation in asphalt concrete. Dissertation (Doctor of Philosophy). University of Maryland, College Park. Disponível em: <http://drum.lib.umd.edu/bitstream/handle/1903/ 12760/Carvalho_umd_0117E_13168.pdf?sequence =1\&isAllowed $=\mathrm{y}>$. Acesso em: 21/02/2015.

Carvalho, R. L. E. (2012) Prediction of permanent deformation in asphalt concrete. Dissertation (Doctor of Philosophy). University of Maryland, College Park. Disponível em: <http://gradworks.umi.com/3517762.pdf>. Acesso em: 18/06/2014.

Choi, Y. T. (2013) Development of a mechanistic prediction model and test protocol for the permanent defor- 
mation of asphalt concrete. Dissertation (Doctor of Philosophy). North Carolina State University at Raleigh. Disponível em: < http://repository.lib.ncsu.edu/ir/bitstream/ 1840.16/8713/1/etd.pdf>. Acesso em: 18/06/2014.

Choi, Y. T.; Subramanian, V. A.; Guddati, M. N. e Kim, Y. R. (2012) An incremental model for the prediction of permanent deformation of asphalt concrete in compression. Transportation Research Record: Journal of the Transportation Research Board, p. 24-35. DOI: 10.3141/2296-03.

Choi, Y. T. e Kim, Y. R. (2014) Implementation and verification of a mechanistic permanent deformation model (shift model) to predict rut depths of asphalt pavement. Road Materials and Pavement Design, v. 15, n. S1, p. 195-218. DOI: 10.1080/14680629.2014.927085.

DNER (1998) DNER-ME 035 Agregados - determinação da abrasão “Los Angeles”. Rio de Janeiro, RJ.

DNER (1995) DNER-ME 043 Mistura betuminosas a quente - ensaio Marshall. Rio de Janeiro, RJ.

DNER (1994) DNER-ME 078 Agregado graúdo - adesividade a ligante betuminoso. Rio de Janeiro, RJ.

DNER (1998) DNER-ME 081 Agregados - determinação da absorção e da densidade de agregado graúdo. Rio de Janeiro, RJ.

DNER (1998) DNER-ME 083 Agregados - análise granulométrica. Rio de Janeiro, RJ.

DNER (1995) DNER-ME 084 Agregado miúdo - determinação da densidade real. Rio de Janeiro, RJ.

DNIT (2003) DNIT-PRO 006 Avaliação objetiva da superfície de pavimentos flexíveis e semi-rígidos. Rio de Janeiro, RJ.

DNIT (2006) DNIT-ES 031 Pavimentos flexíveis - Concreto asfáltico. Rio de Janeiro, RJ.

Dongre, R., D’angelo, J. e Copeland, A. (2009) Refinement of flow number as determined by the asphalt mixture performance tester for use in routine QC/QA practice. Transportation Research Record: Journal of the Transportation Research Board, n. 2127, Washington, D.C., p. 127-136. DOI: 10.3141/2127-15.

EMIS (2015) Euromoney Institutional Investor Company Concessionária Rodovia Presidente Dutra SA (Brasil) Disponível em: <http://www.securities.com/php/companyprofile/BR/Concessionaria_Rodovia_Presidente_Dutra_SA_pt_1145035.html>. Acesso em: 19/06/2015.

Francken, L. (1977) Pavement deformation law of bituminous road mixes in repeated load triaxial compression.

Proceedings of the Fourth International Conference on the Structural Design of Asphalt Pavements, v. I, p. 483-496. The University of Michigan, Ann Arbor, Michigan.
Gibson, N. e Schwartz C.W. (2006) Three-dimensional viscoplastic characterization of asphalt concrete utilizing Perzyna and HiSS methodologies.Proceedings of the $10^{\text {th }}$ International Conference on Asphalt Pavement, v. I, p. 205-214. Cidade de Quebec, Canadá.

Gibson, N. H. (2006) A viscoelastoplastic continuum damage model for the compressive behavior of asphalt concrete. Dissertation (Doctor of Philosophy). University of Maryland, College Park. Disponível em: http://drum.lib .umd.edu/bitstream/handle/1903/3963/umi-umd-3325.pdf . Acesso em: 18/06/2014.

Gibson, N. H.; Kutay, M. E.; Keramat, D. e Youtcheff, J. (2009) Multiaxial strain response of asphalt concrete measured during flow number simple performance test. Journal of the Association of Asphalt Paving Technologists, v. 78, p. 25-66.

Hajj, E. Y.; Ullao, A.; Siddharthan, R.; e Sebaaly, P. E. (2010) Characteristics of the loading pulse for the flow number performance test. Journal of the Association of Asphalt Paving Technologists, v. 79, p. 253-294.

Lacroix, A. T. (2013) Performance prediction of the NCAT test track pavements using mechanistic models. Dissertation (Doctor of Philosophy). North Carolina State University, NC.

Lacroix, A. T. e Kim, Y. R. (2014) Performance predictions of rutting for the National Center for Asphalt Technology test track. Transportation Research Record: Journal of the Transportation Research Board, n. 2457, Washington, D.C., p. 41-50. DOI: $10.3141 / 2457-05$.

Martins, A. T. (2014) Contribuição para a validação do ensaio de resistência ao dano por fadiga para ligantes asfálticos. Dissertação de Mestrado. Universidade Federal do Rio de Janeiro. Rio de Janeiro, RJ. Disponível em: <http://www.coc.ufrj.br/index.php/component/docman/ doc_download/2488-adriana-tinoco-martins-mestrado? Itemid>. Acesso em: 21/02/2015.

Monismith, C. L.; Popescu, L. e Harvey, J. (2006) Rut depth estimation for mechanistic-empirical pavement design using simple shear test results. Journal of the Association of Asphalt Paving Technologists, v. 75, p. 1294-1338.

Nascimento, L. A. H. (2008) Nova abordagem da dosagem de misturas asfálticas densas com uso do compactador giratório e foco na deformação permanente. Dissertação de Mestrado. Universidade Federal do Rio de Janeiro. Rio de Janeiro, RJ. Disponível em: http://www.coc.ufrj.br/ index.php/component/docman/doc_download/1476-luisalberto-herrmann-do-nascimento-mestrado?Itemid>. Acesso em: 18/06/2014.

Onofre, F. C. (2012) Avaliação do comportamento mecânico de misturas asfálticas produzidas com ligantes asfálticos modificados por ácido polifosfórico e polímeros.

TRANSPORTES v. 23, n. 2 (2015), p. 44-55 
Dissertação de Mestrado. Universidade Federal do Ceará, Fortaleza, CE. Disponível em: <http://www.repositorio. ufc.br/bitstream/riufc/11166/1/2012_dis_fconofre.pdf >. Acesso em: 18/06/2014.

Pazos, A. G. (2015) Efeito de propriedades morfológicas de agregados no comportamento mecânico de misturas asfálticas. Dissertação de Mestrado. Universidade Federal do Rio de Janeiro. Rio de Janeiro, RJ. Disponível em: $<$ http://www.coc.ufrj.br/index.php/component/docman /doc_download/2615-abraham-guerrero-pazos?Itemid $>$. Acesso em: 15/09/2015.

Serigos, P. A.; Prozzi, J. A.; Nam, B. H. e Murphy, M. R. (2012) Field evaluation of automated rutting measuring equipment. Technical Report, FHWA/TX-12/0-6663-1.

Subramanian, V. A. (2011) Viscoplastic model with ratedependent hardening for asphalt concrete in compression. Dissertation (Doctor of Philosophy). North Carolina State University, NC.

Uzan, J. (2004) Permanent deformation in flexible pavements. Journal of Transportation Engineering, v. 130, n. 1, p. 6-13. DOI: 10.1061/(ASCE)0733947X(2004)130:1(6).

Von Quintus, H. L.; Mallela, J.; Bonaquist, R.; Schwartz, C. W. e Carvalho, R. L. (2012) Calibration of rutting models for structural and mix design. NCHRP Report 719. Transportation Research Board. Washington, D.C.

Witczak, M. W.; Kaloush, K.; Pellinen, T.; El-Basyouny, M. e Von Quintus, H. (2002) Simple performance test for superpave mix design. NCHRP Report 465. National Research Council, Transportation Research Board. Washington, D.C.

Yun, T. (2008) Development of a viscoplastic constitutive model using a rate-dependent yield criterion for HMA in compression. Dissertation (Doctor of Philosophy). North Carolina State University, NC. Disponível em: <http://repository.lib.ncsu.edu/ir/bitstream/1840.16/3103/1/etd. pdf $>$. Acesso em: 18/06/2014. 